Trainees4trainees: an innovative peer support project for junior doctors across specialties

\author{
Sophie Behrman ${ }^{1 \star}$, Aisling Higham² ${ }^{2}$ Haido Vlachos ${ }^{3}$ \\ and Gerti Stegen ${ }^{1}$ \\ ${ }^{1}$ Oxford Health NHS Foundation Trust; ${ }^{2}$ Oxford University \\ Hospitals, NHS Foundation Trust and ${ }^{3}$ Health Education England - \\ Thames Valley \\ ${ }^{\star}$ Corresponding author.
}

doi: 10.1192/bjo.2021.363

Aims. The BMA's survey results (Caring for the Mental Health of the Medical Workforce, 2019) and HEE's NHS Staff and Learners' Mental Wellbeing Commission report (2019) highlighted declining staff wellbeing. The COVID-19 pandemic has sharpened focus on this and the effects of moral injury on healthcare professionals. Shielding, social distancing and redeployment led to many medical trainees being increasingly isolated at a time of heightened anxiety and adversity. Psychiatry trainees tend to have good access to reflective groups, but this is not customary in other training programmes.

Method. Intervention

"Trainees4trainees" was set up by trainees across specialties as a HEE-TV well-being project, led by the Deanery Trainee Improvement Fellow. Peer support groups are run on Zoom, facilitated by 2 trainees with special training in peer support. Psychiatry trainees have been involved in designing and facilitating groups and training facilitators from other specialties; facilitators have regular supervision from a consultant psychiatrist in medical psychotherapy. Trainees are supported to discuss challenging experiences and think about their emotional responses in a supportive and validating group.

Result. Feedback

We are in the process of formal data collection to assess the impact of the intervention. Informal feedback suggests the groups are a powerful support to individuals who otherwise have no avenue to think about the psychological impact of their experiences. The groups have supported trainees to feel less isolated and bolstered their resilience.

Conclusion. Future plans

We have faced challenges in the practicalities of establishing and maintaining groups. We are working with Training Programme Directors to move towards running the groups in protected time within working hours and advocate that reflective groups, such as our peer support groups, are a key part of future medical and surgical Training Programmes.

\section{Governance of Protecting Patients}

Sureshkumar Bhatt

St. Tammany Parish Coroners Office

doi: 10.1192/bjo.2021.364

Aims. Involuntary commitment is a legal process through which an individual with symptoms of severe mental illness is court-ordered into inpatient or outpatient treatment. These criteria vary between nations. The goal of this presentation is to compare the governance of protecting patients among different parts of the world.

Background. Understanding the relevance of the judicial committeemen in psychiatry is an essential part of good psychiatric practice. A majority of patients who need inpatient psychiatric treatment fall into one of the following categories: dangerous to self, dangerous to others, or gravely disabled.
In the United States, the Parens Patriate doctrine has had great application in the treatment of mentally ill persons, children, and other individuals who are legally incompetent to manage their affairs. The states, which act as parens patriae, can make decisions regarding mental health treatment. State law governs involuntary commitment, and procedures may vary among states.

Method. One of the essential duties of St. Tammany Parish Coroner Office, Louisiana, USA is Mental Health Service, From January 2017 to October 2019, 887 Order of Protective Custody (OPC), 17,838 Physician Emergency Certificates (PEC), and 13096 Coroner Emergency Certificates (CEC) were issued. These certificates allow legal authority to transport a patient to the nearest ER for assessment by physician and mental health providers.

Result. Patients with active Physician Certificate are examined by a coroner according to patient's mental history and clinical presentation. Coroner Certificate helps the treatment facilty detail the patient for diagnosis and treatment for fifteen days.

Conclusion. St. Tammany Parish Coroner Office is fulfilling its responsibility to provide proper mental health to psychiatric patients. It is necessary for each country/state/parish to have legal structure and provide proper care who are dangerous to self or others, or gravely disabled. The procedures of OPC, PEC, and CEC will be presented.

\section{Stigma towards psychiatry: correlating personal experience with existing literature}

Jack Blake ${ }^{1 \star}$ and George El-Nimr ${ }^{2}$

${ }^{1}$ Final Year Medical Student Keele University School of Medicine and ${ }^{2}$ Academic Secretary for the Faculty of Neuropsychiatry at the Royal College of Psychiatrists, Undergraduate Clinical Tutor Keele

University School of Medicine, Consultant Neuropsychiatrist North Staffordshire Combined Healthcare NHS Trust

${ }^{*}$ Corresponding author.

doi: 10.1192/bjo.2021.365

Aims. Stigma towards psychiatry feels rife within medical school and this extends from university life into clinical placements. Mental health remains an unattractive area of medicine and is frequently regarded as subpar by other specialists. Against existing literature, this study compares the authors first hand experiences over the last five years within medical school to evaluate how representative their experiences of stigma in psychiatry are for the wider community and published literature. The study aims to inform the wider discussion on this topic and offer areas where intervention may yield a better perception and hence uptake of this specialism.

Method. Literature review relating to the topic was completed. Studies pertaining to medical students and/or educators views and experiences of psychiatric medical education and clinical placement were included for discussion. A reflection on the first author's specific experiences to date of psychiatry and his intent to pursue psychiatric career was conducted, with careful reference to existing literature. This allowed validating personal experiences in light of shared experience within the medical community in various national and international settings.

Result. Arguably, some non-psychiatric clinicians do inadvertently set the scene early in medical school for the stigma that is to be thrust upon students. This builds upon prospective students ranking psychiatry low for satisfaction, prestige and stating it to be a 'pseudoscience' or words to that effect. The lack of understanding from junior medical students of the role of the psychiatrist sees them associating psychosocial education as equivalent to psychiatry. This reinforces the idea of psychiatry being grounded 